\begin{tabular}{|c|c|c|}
\hline 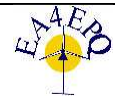 & $\begin{array}{c}\text { European Association for the } \\
\text { Development of Renewable Energies, Environment and } \\
\text { Power Quality (EA4EPQ) }\end{array}$ & $\begin{array}{l}\text { International Conference on Renewable Energies and Power Quality } \\
\text { (ICREPQ'12) } \\
\text { Santiago de Compostela (Spain), 28th to 30th March, } 2012\end{array}$ \\
\hline
\end{tabular}

\title{
Effect of Differential Mass Flow Rate on the Thermal Performance of Double Duct Packed Bed Solar Air Heaters
}

\author{
Prashant Kumar \\ Department of Mechanical Engineering \\ National Institute of Technology, Hamirpur (H.P.) -177005 India
}

Phone Number: +91-1972-254736; fax: +91-1972-223834. E-mail address: prashant_rec@yahoo.co.in

\begin{abstract}
The present paper investigates the effect of differential air mass flow rate on the thermal performance of parallel pass packed bed solar air heater. The range air flow rates over which the parallel pass system yields higher thermal performance as compared to counter pass system have been identified and presented. The effect of fraction of total mass flow rate in the respective ducts of the parallel pass packed bed solar air heater has shown to be dominant parameter in determining the effective thermal efficiency of the heater.
\end{abstract}

\section{Keywords:}

Packed bed; porosity; heater; wire mesh matrix; thermal efficiency; thermohydraulic efficiency

\section{Nomenclature}

$A_{c} \quad$ collector plate area, $m^{2}$

$h_{b} \quad$ convective heat transfer coefficient between bottom insulation and environment, $W / \mathrm{m}^{2} \mathrm{~K}$

$h_{w} \quad$ wind heat transfer coefficient, $W / m^{2} K$

$h_{\text {rgua }}$ radiative heat transfer coefficient between upper glass cover and ambient, $W / m^{2} K$

$h_{r \text { gugl }}$ radiative heat transfer coefficient between glass covers, $W / m^{2} K$

$h_{\text {cgugl }}$ convective heat transfer coefficient between glass covers, $W / m^{2} K$

$h_{\text {rglm }}$ radiative heat transfer coefficient between lower glass and porous material, $\mathrm{W} / \mathrm{m}^{2} \mathrm{~K}$

$h_{r m p} \quad$ radiative heat transfer coefficient between porous material and absorber, $W / m^{2} K$

$h_{\text {cglfu }}$ convective heat transfer coefficient between the lower glass cover and air stream flowing in the upper duct, $W / m^{2} K$

$h_{c m f u}$ convective heat transfer coefficient between the porous material and air stream flowing in the upper duct, $W / m^{2} K$

\footnotetext{
$h_{c p f u}$ convective heat transfer coefficient between the absorber plate and air stream flowing in the upper duct, $W / m^{2} K$

$h_{c p f l} \quad$ convective heat transfer coefficient between the absorber plate and air stream flowing in the lower duct, $W / m^{2} K$

$h_{c b f l} \quad$ convective heat transfer coefficient between the back plate and air stream flowing in the lower duct, $W / m^{2} K$

$I \quad$ insolation/intensity of solar radiation, $W / \mathrm{m}^{2}$
}

\section{Introduction}

Thermal performance of a solar air heater can be enhanced by using a double duct packed bed because this results in higher heat transfer coefficient and minimal heat losses. Further, in order to attain the higher heat transfer coefficient, it is desirable that the flow should be turbulent. However, energy for creation of turbulence has to come from the fan or blower and excessive turbulence means higher friction losses and hence greater power requirement. It is, therefore, necessary to consider the enhancement of thermal performance in combination with friction losses to obtain an effective or net gain in the overall performance. It is desirable to select the type of double duct packed bed solar air heater in such a way that it increases the heat transfer while keeping the friction losses as low as possible. This implies that the effective thermal efficiency of the system, which considers both, thermal as well as friction characteristics, should be as high as possible.

Experimental and theoretical studies concerned with performance of double duct solar air heaters are reviewed in the literature. Mohamad [1] numerically studied the performance of a counter/double-pass solar air heater with and without porous matrix and compared with the performance of single and double glazing conventional solar air heaters. Sopian et al. 
[2] conducted indoor experiments on the counter pass solar collector with and without steel wool as porous media in the second channel. Several combinations of upper and lower channel depths were considered for the thermal performance investigation. Paisarn Naphon [3] studied theoretically the performance of counter flow solar air heater without and with porous media in the lower channel.

The thermal performance of a double-glass double-pass solar air heater with a packed bed above the heater absorber plate was investigated by Ramadan et al. [6]. K. Sopian et al. [7] evaluated the thermal performance of the counter flow collector with porous-nonporous media theoretically and validated experimentally. The performance of single and double-pass solar air heater with fins and steel wire mesh as absorber is investigated experimentally by Omojaro et al. [8] Double glass double flowfinned and v-corrugated plate solar air heater was investigated theoretically and experimentally [9]. The concept of a parallel pass solar air heater with its upper channel packed with iron scrap as porous media was introduced by P. Dhiman et al. [10].

In this paper, the performance comparison between the parallel and counter pass packed bed solar air heater in terms of thermal and effective thermal efficiency is presented and any potential advantages that are associated with the parallel pass arrangement as compared to the double pass packed bed solar air heater operating under similar conditions is explored. The effective thermal efficiency of the solar energy collection system is determined on the basis of actual thermal energy gain reduced by equivalent thermal energy required to generate the power needed for pumping air through the collection system.

\section{Theoretical Analysis}

A mathematical model based on effective heat transfer area has been developed to predict the thermal performance of parallel and counter pass packed bed solar air heaters as shown in Fig. 1. The basic physical equations used to describe the heat transfer characteristics have been developed from the conservation equations of energy. These non-linear equations have been solved by analytical method. The solution is obtained in the form of temperatures of fluid flowing in the upper and lower duct of the double duct system by solving equations simultaneously for the configuration these heaters. The energy-balance equations for the various elements of heater such as upper and lower glass covers, porous material, air flowing in the upper duct, absorber plate, air flowing in the lower duct and back plate may be written, respectively, as follows:
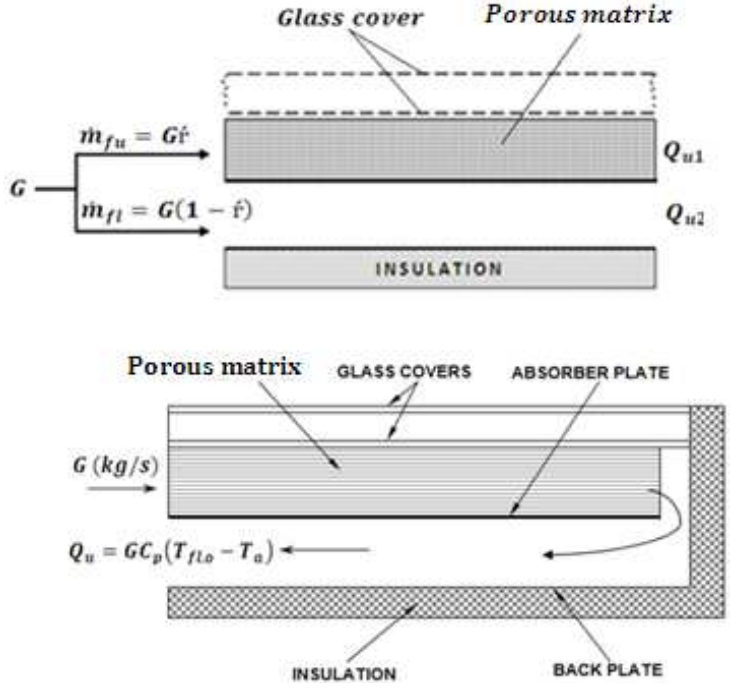

Fig. 1 Schematic diagram of (a) parallel pass and (b) double pass packed bed solar air heater representing the differential mass flow rate.

$$
\begin{aligned}
& \alpha_{g u}=\left(h_{r g u a}+h_{w}\right)\left(T_{g u}-T_{a}\right) \\
& +\left(h_{\text {rgugl }}+h_{\text {cgugl }}\right)\left(T_{g l}-T_{g u}\right) \\
& I \alpha_{g l} \tau_{g}=\left(h_{r g l g u}+h_{c g l g u}\right)\left(T_{g l}-T_{g u}\right)+h_{r g l m}\left(T_{g l}\right. \\
& \left.-T_{m}\right)+h_{c g l f u}\left(T_{g l}-T_{f u}\right) \\
& I \alpha_{m} \tau_{g}^{2}=h_{r g l m}\left(T_{m}-T_{g l}\right)+h_{r m p}\left(T_{m}-T_{p}\right) \\
& +h_{c m f u}\left(T_{m}-T_{f u}\right) \\
& \dot{m}_{f u} C_{p} \frac{d T_{f u}}{d x}=k_{m} \frac{d^{2} T_{f u}}{d x^{2}}+h_{c g l f u}\left(T_{g l}-T_{f u}\right) \\
& +h_{c m f u}\left(T_{m}-T_{f u}\right)+h_{c p f u}\left(T_{p}\right. \\
& -T_{f u} \text { ) }
\end{aligned}
$$

The various heat transfer coefficients of different elements of the solar air heater given in eqn. (1) (7); viz., $h_{r \text { gugl }}, h_{w}, h_{c g l f u}, h_{r g l m}, h_{r p m}, h_{r p b}$, $h_{c p f l}$ and $h_{c b f l}$ are calculated using the correlations given in literature [11].

\section{Performance Parameters}

The main parameters affecting the performance of solar air heaters are the useful thermal energy 
gain, $Q_{u}$, thermal efficiency, $\eta_{t h}$ and effective thermal efficiency, $\eta_{\text {eff }}$.

\subsection{Thermal energy gain, $Q_{u}$}

(a) Thermal energy gain in parallel pass is calculated as [12]:

$$
Q_{u}=Q_{u 1}+Q_{u 1}
$$

where,

$$
\begin{aligned}
Q_{u 1} & =\dot{m}_{f u} C_{p}\left(T_{f u, o}-T_{f u, i}\right) \\
Q_{u 2} & =\dot{m}_{f l} C_{p}\left(T_{f l, o} T_{f l, i}\right)
\end{aligned}
$$

(b)Thermal energy gained by air, $Q_{u}$ in counter pass is calculated as:

$$
Q_{u}=G C_{p}\left(T_{f l, o}-T_{f u, i}\right)
$$

where $G$ is the total mass flow rate and defined as

$$
G=\dot{m}_{f u}+\dot{m}_{f l} \text { and } \dot{m}_{f u}=\dot{m}_{f l}
$$

\subsection{Thermal efficiency of the heater, $\eta_{t h}$}

The thermal efficiency of the solar air heater has been calculated as:

$$
\eta_{t h}=Q_{u} / A_{c} I
$$

\subsection{Effective thermal efficiency, $\eta_{\text {eff }}$}

Since, electrical energy is needed to derive the motor of the blower which forces the air throughout the heater, the fan power $P_{\text {fan }}(\mathrm{W})$ has to be taken into consideration; consequently, the net output power equals $\left(Q_{u}-P_{f a n}\right)$. The necessary instantaneous fan power required for forcing a certain mass flow rate of air is calculated as [13]:

$$
P_{\text {fan }}=P_{\text {flow }} / \eta_{f} \eta_{m} \eta_{t r} \eta_{t c}
$$

where, fan efficiency, $\eta_{f}$, electric motor efficiency, $\eta_{m}$, electric transmission from power plant efficiency, $\eta_{t r}$ and thermal conversion efficiency of power plant, $\eta_{t c}$ are assumed to be $65 \%, 88 \%, 92 \%$ and $35 \%$, respectively [13] and the flow pumping power, $P_{\text {flow }}$ required for forcing the air through duct is calculated as

$$
P_{\text {flow }}=\dot{m}_{f} \Delta P / \rho
$$

The effective thermal efficiency, $\eta_{\text {eff }}$ of the solar air has been calculated as [14]:

$\eta_{\text {eff }}=\left(Q_{u}-P_{\text {fan }}\right) / A_{c} I$

\section{Results and Discussions}

\subsection{Air streams of equal mass flow rates in upper and lower duct, $\dot{m}_{f u}=\dot{m}_{f l}$}

Two air stream of equal mass flow rate are flowing steadily and simultaneously from the upper and lower duct of parallel pass packed bed solar air heater such that the sum of two mass flow rates is equal to the total air mass flow rate, $G$, flowing through the double pass system i.e.

$$
G=\dot{m}_{f u}+\dot{m}_{f l} \text { and } \dot{m}_{f u}=\dot{m}_{f l}
$$

The performance comparison between the parallel and counter pass packed bed solar air heater is presented in Fig. 2. It is observed that the $\eta_{t h}$ of the both heaters increases with increase in total mass flow rate of air, G. This is because the heat removal capacity depends directly on the mass flow rate. Moreover, the $\eta_{t h}$ of the counter pass system is higher than that of parallel pass packed bed system because of reheating of air emerging out from the upper duct in the lower duct.

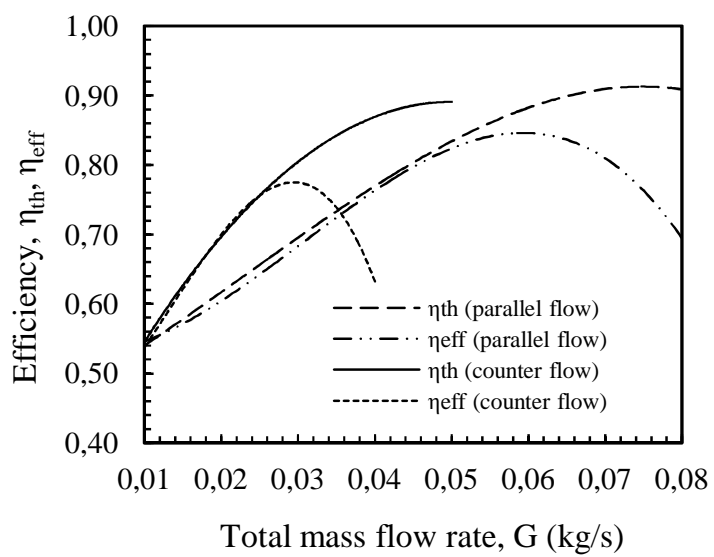

Fig. 2. Effect of mass flow rate on thermal and effective thermal efficiency of parallel and double pass solar air heater $\left(\dot{m}_{f u}=\dot{m}_{f l}\right)$

The $\eta_{\text {eff }}$ of counter pass packed bed system is also higher in comparison to parallel pass packed bed solar air heater upto a mass flow rate of $0.03 \mathrm{~kg} / \mathrm{s}$. However, the $\eta_{e f f}$ of counter pass packed bed solar air heater decreases as the air mass flow rate, G, increases beyond $0.03 \mathrm{~kg} / \mathrm{s}$ whereas, it continues to increase in the parallel pass packed bed solar heater till the air mass flow rate, $\mathrm{G}$ increases upto $0.06 \mathrm{~kg} / \mathrm{s}$. 
It decreases if $\mathrm{G}$ is increased further. Higher $\eta_{\text {eff }}$ in the parallel pass packed bed solar air heater may be attributed to the absence of bending/turning losses. The maximum $\eta_{e f f}$ of the counter packed bed solar air heater is $77 \%$ at the mass flow rate of $0.03 \mathrm{~kg} / \mathrm{s}$ whereas in case of parallel flow packed bed system, the $\eta_{\text {eff }}$ is $85 \%$ at a mass flow rate of $0.06 \mathrm{~kg} / \mathrm{s}$. Hence, $10 \%$ higher $\eta_{\text {eff }}$ can be achieved with parallel pass packed bed solar air heater.

\subsection{Air stream of unequal mass flow rates flowing in upper and lower duct, $\dot{m}_{f u} \neq \dot{m}_{f l}$}

It is considered that two air streams of different mass flow rates flow steadily and simultaneously through the upper and lower ducts of parallel flow packed bed solar air heater, such that the total mass flow rate, $G$, is same as that of counter flow packed bed solar air heater. Let $r$ be the fraction of the total air mass flow rate, $\mathrm{G}$, flowing through the upper duct and remaining (1- r), through the lower duct i.e.

$$
\begin{aligned}
& G=\dot{m}_{f u}+\dot{m}_{f l} \text { and } \dot{m}_{f u} \neq \dot{m}_{f l} \text { where } \\
& \dot{m}_{f u}=G \text { ŕ and } \dot{m}_{f l}=G(1-\dot{\mathrm{r}})
\end{aligned}
$$

The values of fraction, $\mathrm{r}$ in the range of 0.2 to 0.8 of the total air mass flow rate, $\mathrm{G}$ ranging from 0.01 to $0.05 \mathrm{~kg} / \mathrm{s}$ were considered for the comparison of the two designs of packed bed solar air heaters.

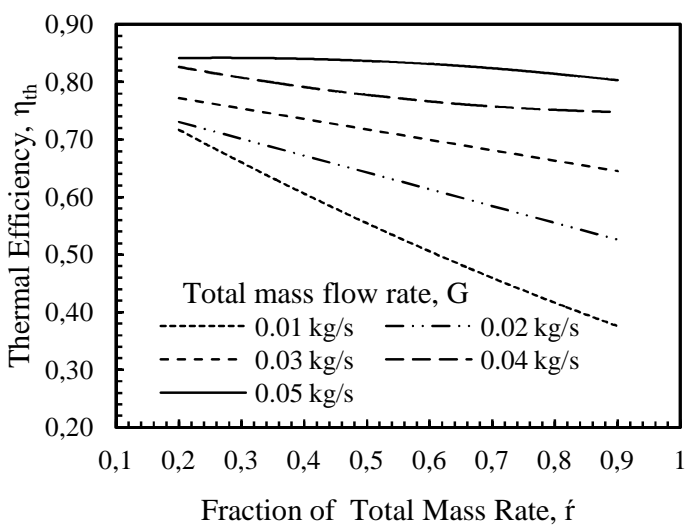

Fig. 3. Effect of fraction of total mass flow rate on thermal efficiency of parallel flow packed bed solar air heater

Effect of the fraction of total mass flow rate on the $\eta_{t h}$ and $\eta_{e f f}$ of the parallel pass solar air heater is presented in Figs. 3 and 4, respectively. The $\eta_{t h}$ and $\eta_{\text {eff }}$ of the heater increases with increase in total mass flow rate ranging from 0.01 to $0.05 \mathrm{~kg} / \mathrm{s}$. It is predicted and shown in Fig. 3 that the $\eta_{t h}$ of the parallel flow packed bed solar air heater is higher at the lower value of fraction of particular total air mass flow rate, $\dot{r}$ and decreases with increase in value of $\dot{z}$.
The rate of decrease with increasing fraction, $z$, is more at lower total mass flow rate, G. A similar trend for the $\eta_{\text {eff }}$ (Fig. 4) is observed. At $\mathrm{G}$ equal to 0.05 $\mathrm{kg} / \mathrm{s}$, the drop in $\eta_{\text {eff }}$ is very sharp with increasing $\dot{r}$. This may be due to larger pressure drop in the upper duct and thermal losses.

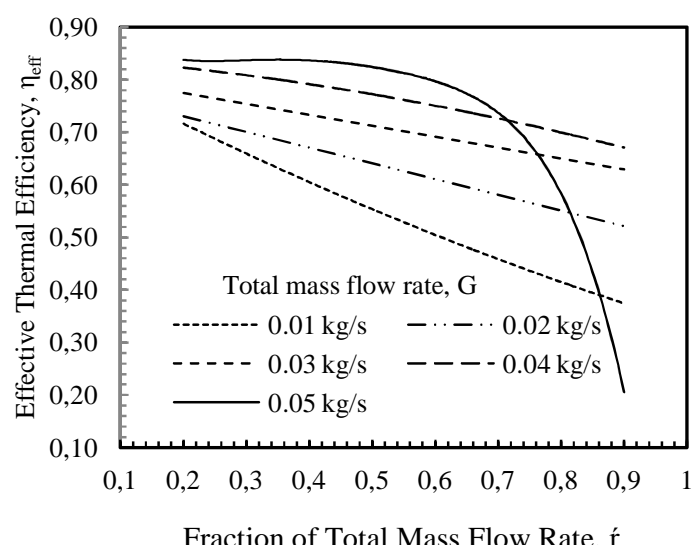

Fig.4. Effect of fraction of total mass flow rate on effective thermal efficiency of parallel flow packed bed solar air heater

The $\eta_{t h}$ and $\eta_{e f f}$ of parallel pass solar air heater is compared with counter pass packed bed system subjected to different fraction of total mass flow rates and presented in Table 1.

Table 1. Predicted thermal and effective thermal efficiency

\begin{tabular}{|c|c|c|c|c|c|}
\hline \multirow[t]{2}{*}{$\begin{array}{c}\text { Total } \\
\text { Mass } \\
\text { Flow } \\
\text { Rate, } \\
\mathrm{G}(\mathrm{kg} / \mathrm{s})\end{array}$} & \multicolumn{3}{|c|}{$\begin{array}{l}\text { Parallel flow Packed } \\
\text { Bed Solar Air Heater }\end{array}$} & \multicolumn{2}{|c|}{$\begin{array}{c}\text { Counter flow } \\
\text { Packed } \\
\text { Bed Solar Air } \\
\text { Heater }\end{array}$} \\
\hline & $\dot{r}$ & $\eta_{\text {th }}$ & $\eta_{\text {eff }}$ & $\eta_{\text {th }}$ & $\eta_{\text {eff }}$ \\
\hline \multirow{4}{*}{0.01} & 0.2 & 0.72 & 0.72 & \multirow{4}{*}{0.54} & \multirow{4}{*}{0.54} \\
\hline & 0.4 & 0.59 & 0.59 & & \\
\hline & 0.6 & 0.52 & 0.51 & & \\
\hline & 0.8 & 0.44 & 0.43 & & \\
\hline \multirow{4}{*}{0.02} & 0.2 & 0.78 & 0.78 & \multirow{4}{*}{0.71} & \multirow{4}{*}{0.70} \\
\hline & 0.4 & 0.61 & 0.61 & & \\
\hline & 0.6 & 0.60 & 0.59 & & \\
\hline & 0.8 & 0.58 & 0.57 & & \\
\hline \multirow{4}{*}{0.03} & 0.2 & 0.80 & 0.81 & \multirow{4}{*}{0.81} & \multirow{4}{*}{0.77} \\
\hline & 0.4 & 0.73 & 0.72 & & \\
\hline & 0.6 & 0.68 & 0.66 & & \\
\hline & 0.8 & 0.68 & 0.65 & & \\
\hline \multirow{4}{*}{0.04} & 0.2 & 0.82 & 0.82 & \multirow{4}{*}{0.86} & \multirow{4}{*}{0.63} \\
\hline & 0.4 & 0.80 & 0.79 & & \\
\hline & 0.6 & 0.76 & 0.75 & & \\
\hline & 0.8 & 0.75 & 0.70 & & \\
\hline \multirow{4}{*}{0.05} & 0.2 & 0.84 & 0.84 & \multirow{4}{*}{0.90} & \multirow{4}{*}{-0.81} \\
\hline & 0.4 & 0.84 & 0.83 & & \\
\hline & 0.6 & 0.83 & 0.80 & & \\
\hline & 0.8 & 0.81 & 0.58 & & \\
\hline
\end{tabular}
of parallel and counter pass packed bed solar air heaters 
The $\eta_{t h}$ of the parallel pass packed bed system is $72 \%$ and $44 \%$ at $z$ equal to 0.2 and 0.8 repectively of the fixed/total air mass flow rate of $0.01 \mathrm{~kg} / \mathrm{s}$ and the corresponding $\eta_{\text {eff }}$ is $71.6 \%$ and $43 \%$ repectively whereas, the $\eta_{t h}$ and $\eta_{\text {eff }}$ of counter flow packed bed solar air heater at $0.01 \mathrm{~kg} / \mathrm{s}$ mass flow rate is $54 \%$ as shown in Table 6.1. Therefore, the percentage enhancement of $33.3 \%$ and $33.1 \%$ in $\eta_{t h}$ and $\eta_{\text {eff }}$ respectively at $\dot{r}$ equal to 0.2 is achieved for parallel pass heater in comparison to counter pass packed bed solar air heater (Table 1). Similar values at different $\mathrm{G}$ is reported and observed that the gain in $\eta_{\text {eff }}$ for parallel pass heater is more at higher values of $\mathrm{G}$.

\section{Conclusion}

Following conclusion has been drawn from this study:

- The counter pass design is found to be more efficient compared to parallel pass in terms of thermal efficiency.

- Effective thermal efficiency of the counter pass heater is higher than parallel pass upto the total mass flow rate of $0.03 \mathrm{~kg} / \mathrm{s}$. Increasing mass flow rate beyond $0.03 \mathrm{~kg} / \mathrm{s}$, the effective thermal of counter pass design decreases where as it continues to increase in case of parallel pass until the total mass flow rate of $0.06 \mathrm{~kg} / \mathrm{s}$. Parallel pass design achieved a $10 \%$ higher effective thermal efficiency when air steadily flowed at equal mass rates in its upper and lower ducts compared to the counter pass design.

- Effect of fraction of total mass flow rate on the thermal and effective thermal efficiency of the parallel pass packed bed solar air heater was studied. It is observed that the parallel pass packed bed solar air heater has higher thermal and effective thermal efficiency than counter pass packed bed solar air heater at $i$ less than 0.5 . Thermal and effective thermal efficiency of parallel pass packed bed solar air heater is $84.3 \%$ and $84.2 \%$ respectively at $\dot{r}$ equal to 0.2 of the total mass flow rate of $0.05 \mathrm{~kg} / \mathrm{s}$ whereas is $90 \%$ and $-81 \%$ respectively for the counter flow packed bed. Therefore, parallel pass packed bed solar air heater is one of the important and attractive design to improve the effective thermal efficiency at higher mass flow rates.

\section{References}

[1] A.A. Mohamad, "High efficiency solar air heater", Solar Energy 1997, vol. 60, pp. 71-76.

[2] K. Sopain, Supranto, W.R.W. Daud, M.Y. Othman and Yatim B, "Thermal performance of the double pass solar collector with and without porous media", Renewable Energy 1999, vol. 18, pp. 557-564.

[3] N. Paisarn, "Effect of porous media on the performance of double-pass flat plate solar air heater", International Communication in Heat and Mass Transfer 2005, vol. 32, pp. 140-150.

[4] NE Wijeysundera, LE Ah and LE Tjioe, "Thermal performance study of two-pass solar air heat heaters", Solar Energy 1982, vol. 28, pp. 363-370.

[5] N. Paisarn and B. Kongtragool, "Theoretical study on heat transfer characteristics and performance of the flatplate solar air heaters", International Communication in Heat and Mass Transfer 2003, vol. 30, pp. 1125-1136.

[6] M.R.I. Ramadan, A.A. El-Sebaii, S. Aboul-Enein, E. El-Bialy, "Thermal performance of a packed bed double-pass solar air heater", Energy 2007, vol.32, pp. $1524-1535$

[7] K. Sopain, M.A. Alghoul, M. Ebrahim Alfegi, M.Y. Sulaiman and E.A. Musa, "Evaluation of thermal efficiency of double-pass solar collector with porousnonporous media”, Renewable Energy 2009, vol. 34, pp. $640-645$.

[8] A.P. Omojaro and L.B.Y. Aldabbagh, "Experimental performance of single and double pass solar air heater with fins and steel wire mesh as absorber", Applied Energy 2010, vol. 87, pp. 3759-3765.

[9] A.A. El-Sebaii, S. Abou-Enein, M.R.I. Ramadan, S.M. Shalaby, B.M. Moharram, "Thermal performance investigation of double pass-finned plate solar air heater", Applied Energy2011, vol.88, pp.1727-1739.

[10] D. Prashant, N.S. Thakur, K. Anoop and S. Satyender, "An analytical model to predict the thermal performance of a novel double flow packed bed solar air heater', Applied Energy 2011, vol.88, pp. 21572167.

[11] H.P. Garg, Advances in solar energy technology. Dordrecht (1987, Reidel Publishing Company.

[12] M.S. Sodha, N.K. Bansal and D. Singh, "Analysis of non porous double flow solar air heater", Applied Energy 1982, vol. 12, pp. 251-258.

[13] M.K. Mittal and L. Varshney, "Optimal thermalhydraulic performance of a wire mesh packed bed solar air heater', Solar Energy 2006, vol. 80, pp. 1112-1120.

[14] N.S. Thakur, J.S. Saini and S.C. Solanki, "Heat transfer and friction factor correlations for packed bed solar air heater for a lower porosity system", Solar Energy 2003, vol. 74, pp. 319-329. 